\title{
Students' Participation in a Social Media Enhanced Learning Environment
}

\author{
http://dx.doi.org/10.3991/ijet.v8iS2.2741 \\ A.-M. Tervakari, K. Silius and M. Kailanto \\ Tampere University of Technology, Tampere, Finland
}

\begin{abstract}
In this article, we introduce the results of a study concerning visualizations of students' participation and activity in TUT Circle, a social media enhanced web service for learning, networking, and communication. Welldesigned visualizations can provide useful information for teachers to improve pedagogical practices and the quality of online courses. Visualization enables students to monitor their own activity levels and performance processes, and make strategic adjustments to improve them.
\end{abstract}

Index Terms-Learning analytics, participation, peer learning, visualization of user data.

\section{INTRODUCTION}

Peer learning that emphasizes students' learning with and from each other, often apart from teachers, has become widespread teaching practice in universities. The main purpose has been to promote students' ability to work together in teams, as is required by employers. At a same time, an interest in using social media for educational purposes has been on the increase [1]. The use of social media has been thought to facilitate collaboration, communication, and networking among students as well as to promote participation and social interaction, which are strongly related to effective and enjoyable online learning experiences [2]. However, using social media or assigning students tasks to interact and collaborate does not guarantee the students will interact or collaborate effectively with their peers. Particularly among university students, lack of time and a tendency to postpone completion of important tasks (i.e. procrastination) can decrease or even hinder social interaction and participation within online learning environments, which can have a negative impact on peer learning and learning in general. Indeed, procrastination and lack of time are usually related to a failure of online learning and to a poor academic performance [3] [4] [5].

In order to promote and support students' ongoing participation and peer learning during an online course, information about the students' activity, interaction, and participation is required, while the course is still in progress. The recording social media activities offers the potential to gather a large amount of rich data about students' actions for analysis. Social media platforms include several functionalities to facilitate publishing, indexing, and tracking of user-generated content and networking, such as friending, following, messaging, and status updating. In addition, several technical solutions, like RSSfeeds allowing information sharing, web services enabling machine-machine interaction, and mobile devices expanding the availability and localization of different services, allow users to interact and collaborate over different chan- nels. Information about users' actions are recorded and stored automatically in the log data of social media platforms, which make large and rich data sets available for further use [6].

However, user data stored in social media platforms are rarely used for developing learning and teaching. These educational datasets offer unused opportunities for the evaluation of learning theories, learner feedback and support, early warning systems, learning technology, and the development of future learning applications. The importance of learning analytics has been increasingly recognized, for example, by educators, research institutes, and software providers [7]. Learning analytics can be defined as a collection of methods for measuring, collecting, analyzing and reporting data about learners, their actions, and contexts, which can be utilized for understanding and optimizing learning. Data can also provide useful information about students' learning types and activity, and help identify students who may be at risk of failing or dropping out [8].

A main challenge in using user data for developing learning and teaching is that the data is difficult to utilize. Before the data stored in log files can be utilized to help make decisions on potential pedagogical strategies, actions, or interventions which may be used to promote students' participations and peer-learning, the data need to be gathered, analyzed, and interpreted [4] [9]. There are several data mining techniques, sophisticated analyzing methods, and visualization tools that can provide useful information for both teachers and students. However, these methods and tools are not usually developed for pedagogical purposes, and may be cumbersome for use by teachers and students [9] [10]. Another challenge is the quantity of data. Large amounts of data can be difficult for people to analyze, interpret, and understand, because processing data requires complex cognitive processes. However, if the data are packaged and presented in a correct, clear, and effective way, humans can process an incredible amount of data [11] [12]. Visualization can help, for example, by increasing memory and processing the available resources, reducing the search for information, enhancing the recognition of patterns, enabling perceptual inference operations, and using perceptual attention mechanisms for monitoring. From the users' perspective, visualizations can help them better understand the data. However, to be understood, the data used should be familiar and interesting to users. A good visualization will confirm what they already know, and provide several insights into the data [13].

In order to help teachers and students analyze participation and peer-learning processes during courses, the Intelligent Information Systems Laboratory (IISLab) at Tam- 
pere University of Technology (TUT) has developed a pedagogical data analyzing and visualization tool that was implemented in the social media enhanced learning environment called TUT Circle ${ }^{1}$. The tool supports the analysis and visualization of $\log$ data in the TUT Circle, and offers possibilities to monitor the students' activity and participation during the course in real time. To examine the usefulness of the visualizations, the IISLab organized a teaching experiment in autumn 2012. During the teaching experiment, the TUT Circle was used as a learning environment, and the students were offered the visualizations in order to support them to monitor their peer learning activities, and to motivate them to participate. The visualizations were also offered to the teacher for monitoring the students' actions during the course. The aims of the teaching experiment conducted were to determine if: 1) students found the use of visualizations to present their activities and participation during the course interesting and motivating, and 2) visualizations are useful for evaluating impacts of pedagogical interventions during the course.

This study is part of a Finnish national project called Campus Conexus carried out from 2009 to 2013, and financed by the European Social Fund. Five Finnish universities are participating in the project, with an aim to study how students engage in university studies, by enriching learning experiences and enhancing students' personal, intellectual, collegial, and professional development [1]. Another aim of the project is to develop a social media enhanced learning environment called the TUT Circle to support students' collaboration, networking, and study, which the IISLab is responsible for. The TUT Circle is built on a content management framework called Drupal ${ }^{2}$, and contains all the basic functionalities of a modern social media web service. The development work of the TUT Circle is based on results of the earlier studies conducted by the IISLab. Among other things, the IISLab has studied quality factors of the social media enhanced learning environment, students' motivation to use that kind of environment, and possibilities to support peer-to-peer learning and networking among students through social media [14] [15] [16] [17]. A significant part of that development work has been the development and research of methods for analyzing and visualizing $\log$ data collected from the TUT Circle in order to make students' actions visible.

\section{MONITORING STUDENTS' PARTICIPATION}

Participation is essential for effective collaborative learning interactions and peer learning. Peer learning is considered to include learning activities that are mutually beneficial and involve the sharing of knowledge, ideas, and experiences among participants who are in similar situations. Peer learning occurs when one student collaborates, communicates, and shares knowledge with a peer [18] [19]. When all the students actively participate in a course's learning activities, the amount of information available to the students increases, which maximizes the students' learning potential [3] [4]. While active participation is important to achieve better learning results, passive participation, like reading content and messages produced by other students (i.e. learning through observation), can also enhance learning performances [3] [4].

In addition to a high level of motivation to participate, good academic performance in an online course requires self-discipline and good time management skills. A problematic phenomenon from the viewpoint of peer learning is procrastination, which is defined as a tendency to postpone important tasks required to be completed by a specific deadline [3] [5]. Procrastination can impact on peer learning in many negative ways. If the majority of students submit their answers to a course question just before the deadline, this gives them little time to discuss or develop a shared understanding of a subject, which makes true conversation impossible. Submitting answers during the last few hours before the deadline also limits opportunities for learning through observation [3] [17]. Students have also reported negative feelings, such as pressure and a sense of superficial learning related to procrastination [17]. However, students have individual differences in their abilities to manage time, and in the ways they participate in learning processes. Some students are active procrastinators, who make a conscious decision to procrastinate. One reason for this is that they may wish to read other students' answers before sending their own. Passive procrastinators can be students with motivational problems who have difficulties completing their tasks on time [3] [5].

In order to avoid procrastination and promote ongoing participation, which is vital for learning, careful instructional design is required. Problem-based and inquirybased learning methods are considered to increase students' motivation for learning, and problem-based or inquiry-based assessments are thought to promote active participation, interaction, and knowledge sharing among students. Learning activities should also occur evenly during the course so students are able to manage their workload. However, students' participation is largely determined by the way they are to be assessed. Assessment guidelines with clear and fair assessing and grading processes help students see the objectives of studying, and to understand what is expected from them [19]. Even so, in spite of careful instructional design, strategic pedagogical interventions may be required to motivate and activate some students during the course.

While traditional approaches for monitoring students' actions, such as statistics about their activities, offer only limited possibilities for evaluating the level of students' participation during the course, learning analytics with the use of social network analysis (SNA), dynamic visualizations, and other sophisticated methods for gathering, processing, analyzing, and evaluating information about learning and teaching can make students' actions visible, and offer interesting possibilities to monitor the evolution of the students' participation during the course, and, further, to evaluate the quality of the instructional design of the course [8] [9] [17] [20].

In analyzing learning data, a key focus is on users' actions and the content they produce. Well-designed visualizations of user data can provide teachers valuable insight into their students' activity and participation, and thus help evaluate the quality of a course's instructional design. Visualizations may also help students monitor and evaluate their own performance processes and learning outcomes, and make strategic adjustments to improve them [8]. From a social perspective, learning analytics is related 
to a combination of individual knowledge and skills, the environment, use of tools, and the ability to work together. In understanding learning in this context, we must also pay attention to group processes of knowledge construction. The focus must be not only on learners, but also on their tools, pedagogical targets, teaching methods, situation, and environment [6].

By applying the methods of learning analytics, designers of visualizations can integrate technical, social, and pedagogical dimensions better which support the evaluation of online learning and teaching from the viewpoint of pedagogical usability [8]. The term "pedagogical usability" is denoted whether the tools, content, interface, and the tasks of the web-based learning environments support various learners to learn in various learning contexts, according to selected pedagogical objectives. The methods of learning analytics can also help evaluate if the instructional design of the course is based on the appropriate educational theory, and if the learners' unique skills and needs, such as motivation, diversity, and growth, are taken into consideration [21] [22].

\section{TWO TEACHING EXPERIMENTS}

Hypermedia students studying technology can be seen as early adapters of technological innovation. They are more adept in terms of the comprehension and manipulation of complex technology than students of other subjects [23]. In autumn 2011, the IISLab organized a teaching experiment in the promotion of hypermedia student networking, collaboration, and communications using the TUT Circle during online course named Usefulness of Web-Based Services.

During the experiment, log data collected from the TUT Circle were analyzed using SNA methods, and visualized for creating dynamic time-driven animations in order to help teachers' verify student participation (i.e. interaction among students and content). In addition, information about students' experiences of participation was collected by a survey in order to understand their behavior. The results of the analysis and visualizations of $\log$ data showed that the students actively read content produced by others; however, only a few students voluntarily commented on content created by other students, even though they were motivated to comment by the offer of extra points. In addition, most of the students' actions happened around the assignment deadlines. According to the students, procrastination had a negative impact on their learning, because answering just before the deadlines made true conversation difficult. The students thought that the main reason for procrastination was that they were busy with other courses and tasks, and suggested that they could be encouraged to return their assignment early if they were given incentive to do so, such as the offer of extra points. However, the procrastinators were not a totally homogeneous group. Some of the students seemed to make a conscious decision to procrastinate, whereas others seemed to fail to complete their tasks on time due to indecision and lack of motivation [17] [20].

In autumn 2012, a teaching experiment similar to the experiment organized in 2011 was carried out. The IISLab organized an online course called Usefulness of WebBased Services, in which 33 hypermedia students participated. The course was consisted of a group-work project with an aim of evaluating the usefulness of a web-based service and independent working periods on the web for studying basic theories of quality assurance. Like the previous year, the TUT Circle was used as a learning environment in order to promote students' networking, collaboration, and communications on the web. Students were offered online learning material presenting basics theories for evaluating the quality and usefulness of web-based services for self-study, and their thinking was activated by requiring them to contribute assignments by writing messages on a discussion forum related to a theme given by the teacher. Based on the results from the previous teaching experiment, the instructional design of the course was developed. In contrast to the earlier experiment, there were six assignments instead of nine, and the students were also given more time to contribute each assignment. In order to promote active participation, students were required to write two or three messages instead of one to complete each task. The teacher also participated in the online discussion in order to activate the students. In addition, students were motivated to avoid procrastination by offering them extra points to be added to their final score if they wrote at least one message during the first three days after the assignment was opened.

In order to help the students monitor and evaluate their participation and activity levels, and perhaps increase their motivation to improve their performance, three different visualizations were presented to the students. Visualization \#1 was a time-driven animation presenting the development of the students' activity, such as returning assignments as written messages during the course in the TUT Circle. Visualization \#2 was an interactive visualization that presented the activity and participation of the student group. Each student was also offered a personalized interactive visualization (\#3) that presented his/her own activity and participation. The students also responded to a web survey that aimed to gather information about their opinions on the usefulness of the visualizations, and their opinions on participation and procrastination.

The time-driven animation presenting the development of the students' activity (\#1) and the interactive visualization that presented the activity and participation of the student group (\#2) were also presented to the teacher of the course in order to help her evaluate the evolution of the students' participation and the quality of the instructional design. According to the principles of participatory design the teacher of the course was actively involved in development of the visualizations [24]. As a member of the design team the teacher participated in brainstorming sessions, production of specification for the visualizations, design decisions, and evaluation of visualization mockups and prototypes. Notes produced by the design team offered plenty of information about the usefulness of the visualizations from teachers' viewpoint.

\section{ANALYSIS AND RESULTS}

The students participating in the course responded to the web survey as part of their course assignment. The survey was completed in autumn 2012 by 24 students. At first, the students were asked to rate their agreement or disagreement with seven survey statements on a 5-point Likert-type scale. The aim was to determine if the students found peer-learning activities useful for their learning. Secondly, the students were asked to rate the usefulness of the visualizations provided using a 7-level semantic differential (otherwise known as a bipolar rating scale) with 
contrasting adjectives at each end ( $0=$ totally useless/ $6=$ very useful). In addition, there were open-ended questions in the survey with an aim to gather information about their experience on participation and procrastination, to find out how the students interpreted the visualizations presented, and why they considered the visualizations to be useful or useless.

The qualitative data from open-ended questions of survey were analyzed using content analysis, a method used to examine the meanings, themes, and patterns that were manifest or latent in the students' answers, and to identify similarities and differences among answers. The content analysis was also used for analyzing documents produced by the design team in order to identify and interpret words, phrases and sentences describing usefulness of visualizations. To ensure the validity of the content analysis, researcher triangulation was used. It should be noted that both the Likert-scale and semantic differential scale are ordinal scales, and, consequently, averages and standard deviations have no valid interpretations. They can still offer useful information to construct an overall view of the phenomenon under investigation.

\section{A. Online students' experiences in peer learning}

According the results from the first part of the survey, most of the students (83\%) agreed or strongly agreed that sharing their own content, links, and other resources via the TUT Circle was useful for their learning. However, only roughly half of them (46\%) agreed or strongly agreed that content, links, and other resources shared by other students were useful for their learning. (See statements 1 and 7 in Table 1.)

TABLE I.

Division PERCENT OF THE STUDENTS ACCORDING TO THEIR LEVEL OF AGREEMENT TO STATEMENTS $(\mathrm{N}=24)$

\begin{tabular}{|l|l|l|l|l|l|}
\hline \multicolumn{1}{|c|}{ Statements } & A & B & C & Av. & Stdv. \\
\hline $\begin{array}{l}\text { 1. Sharing content, links, and } \\
\text { other resources in the TUT } \\
\text { Circle was useful for my learn- } \\
\text { ing. }\end{array}$ & 13 & 4 & 83 & 3.92 & 1.02 \\
\hline $\begin{array}{l}\text { 2. Presenting my ideas, opin- } \\
\text { ions, and questions related to the } \\
\text { subject matter in the TUT Circle } \\
\text { was useful for my learning. }\end{array}$ & 8 & 46 & 46 & 3.42 & 0.88 \\
\hline $\begin{array}{l}\text { 3. Commenting on the messages } \\
\text { and works of other students in } \\
\text { the TUT Circle was useful for } \\
\text { my learning. }\end{array}$ & 29 & 21 & 50 & 3.33 & 1.17 \\
\hline $\begin{array}{l}\text { 4. Receiving comments on my } \\
\text { own messages and works in the } \\
\text { TUT Circle was a positive expe- } \\
\text { rience. }\end{array}$ & 13 & 33 & 54 & 3.58 & 1.06 \\
\hline $\begin{array}{l}\text { 5. Comments on my own mes- } \\
\text { sages and works received in the } \\
\text { TUT Circle was useful for my } \\
\text { learning. }\end{array}$ & 21 & 25 & 54 & 3.29 & 0,91 \\
\hline $\begin{array}{l}\text { 6. Reading messages and works } \\
\text { written by other students was } \\
\text { useful for my learning. }\end{array}$ & 17 & 38 & 46 & 3.29 & 0.75 \\
\hline $\begin{array}{l}\text { 7. Content, links, and other } \\
\text { resources shared by other stu- } \\
\text { dents were useful for my learn- } \\
\text { ing. }\end{array}$ & 29 & 25 & 46 & 3.21 & 1.05 \\
\hline
\end{tabular}

$\mathrm{A}=$ disagreed or strongly disagreed $\mathrm{B}=$ neutral $\mathrm{C}=$ agreed or strongly agreed

While half of the students (46\%) agreed or strongly agreed that presenting their ideas, opinions, and questions in the TUT Circle was useful for their learning, only $8 \%$ of them disagreed or strongly disagreed with that statement. Forty-six per cent of the students agreed or strongly agreed that reading messages and works written by other students was useful in their learning (See statements 2 and 6 in Table 1).

Roughly half of the students seemed to think that comments were useful in their learning. The students seemed to have different opinions concerning whether commenting on the works of other students was useful for their learning. Half of respondents $(50 \%)$ agreed or strongly agreed that commenting on the works of other students was useful, whereas one-third of them $(30 \%)$ disagreed or strongly disagreed. Half of the students (54\%) agreed or strongly agreed that receiving comments was a positive experience, and $13 \%$ had the opposite opinion. Fifty-four per cent of the students agreed or strongly agreed that comments on their own contributions written by other students were useful for their learning (See statements 3, 4 , and 5 in Table 1).

\section{B. Visualizations of students ' participation}

Three different visualizations presenting the evolution and level of the students' participation and activity over time during the course were presented to them in order to help them monitor and evaluate their performance processes.

TABLE II.

Division PERCENT OF THE STUDENTS ACCORDING TO THEIR RATINGS ON USEFULNESS OF THE VISUALIZATIONS ( $\mathrm{N}=24)$

\begin{tabular}{|l|c|c|c|c|c|}
\hline \multicolumn{1}{|c|}{ Visualization } & A & B & C & Av. & Stdv. \\
\hline $\begin{array}{l}\text { Visualization \#1: Time-driven } \\
\text { animation presenting the de- } \\
\text { velopment of the students' } \\
\text { activity and participation. }\end{array}$ & 18 & 21 & 63 & 3.71 & 1.60 \\
\hline $\begin{array}{l}\text { Visualization \#2: Interactive } \\
\text { visualization representing } \\
\text { students' participation over } \\
\text { time. }\end{array}$ & 26 & 22 & 52 & 3.35 & 1.70 \\
\hline $\begin{array}{l}\text { Visualization \#3: Personalized } \\
\text { interactive visualization repre- } \\
\text { senting each student's partici- } \\
\text { pation over time. }\end{array}$ & 57 & 17 & 26 & 2,48 & 1.27 \\
\hline
\end{tabular}

$\mathrm{A}=$ useless $\mathrm{B}=$ neutral $\mathrm{C}=$ useful

Visualization \#1 was a time-driven animation presenting the development of the students' activity, such as returning assignments as written messages during the course in the TUT Circle. In order to create the visualization, the log data were collected from the TUT Circle, modeled into a network that represented the interactions between students and the course content using SNA methods, and then visualized using Gource ${ }^{3}$, a software version control visualization tool [17].

Figs. 1-3 present three snapshots from interesting time points related to the second assignment of the course. In the figures, red nodes represent the students' assignments (i.e. forum discussions), nodes of other colors represent other content, such as course information, and comments written in discussions are represented by the tree structures under the related nodes. The second assignment that required the students to write three different messages in the discussion forum was opened to the students on Tuesday morning. The deadline for the assignment was two 

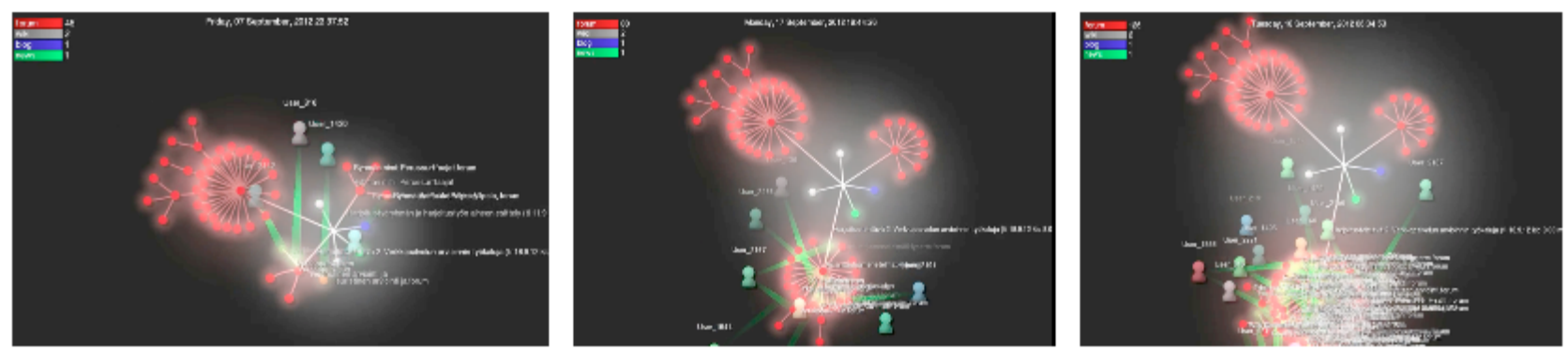

Figures 1-3. Three snapshots from interesting time points related to the second assignment. Three days after opening the assignment, only five students had written their first message (Fig. 1). Almost two weeks later, 12 hours before the deadline, less than half of the students (45\%) had participated (Fig. 2). Most of the students returned their assignments just before the deadline. Fig. 3 presents the situation 90 minutes before the 8.00 a.m. deadline on Tuesday morning.

weeks later on Tuesday morning at 8.00 a.m. Three days after opening the assignment, only five students had written their first message despite the extra points offered for early participation (Fig.1). Almost two weeks later on Monday, 12 hours before the deadline, less than half of the students (45\%) had participated, and only $38 \%$ of their required messages were written (Fig. 2). Most of the students' participation occurred during the last few hours before the deadline. Fig. 3 presents the situation 90 minutes before the 8.00 a.m. deadline on Tuesday morning. The visualizations clearly show students' burst-like behavior when they return their assignments just before the deadline. This kind of behavior was observed during the entire course for all the assignments.

All of the respondents interpreted that the visualizations represented a development of their activity in the TUT Circle during the course, and all of them recognized the phenomenon of procrastination.

"Most of the students are answering assignments just before the deadline. In practice, most activities happened after $10 \mathrm{pm}$ in last night before the deadline. Only a few of the students completed their task in time." - Respondent $8^{4}$

According the results of the survey, almost two thirds of the students $(63 \%)$ found visualization $\# 1$ to be useful (see Table 2). One of the open-ended questions in the survey aimed to elicit an explanation for this. According to the respondents, the visualization was a demonstrative $(13 / 24)$ and fascinating $(5 / 24)$ way to monitor their performance during the course.

"First of all, it was interesting to see how deadlines impact on students' actions. On the other hand, it was easy to see how different issues, messages, and comments are related to each other." - Respondent 3

However, some of the students questioned the usefulness of the visualization $(6 / 24)$, and considered it unclear and difficult to interpret $(5 / 24)$.

"It [visualization] shows how people act during the time, but nothing more." - Respondent 9

Interactive visualization \#2 utilizing Crossfilter ${ }^{5}$ (Fig. 4), JavaScript library, was implemented in the TUT Circle, which enabled the students to interact directly with the visualizations and experience visual analytics. The visualization allowed the students to explore their activity and participation history using live histograms. The students could click and drag on charts to filter information by di-

4 The responses of participants were originally in Finnish, and they have been translated into English.

$5 \quad$ http://square.github.com/crossfilter/ mensions such as time, unique viewers (i.e. number of single persons) per content, total views per content, and date. Visualizations presented the activity and participation of the student group, and were made available to all students.

Visualization \#2 shows the activity and participation of all the students of the course, according to the dimensions of time, unique viewers, views, and date (see Figure 4). The visualizations show that students had worked during the daytime and evenings, but also at night. Students' activity increased from 8.00 p.m. towards midnight, at which point it decreased and increased again before the deadlines at 8.00 a.m. In the histogram presenting the distribution of students' participation, all peaks are at the date of a deadline. This indicates a strong element of procrastination up until the assessment due date.

Half of the students $(52 \%)$ found this visualization useful, while a quarter $(26 \%)$ found the visualization to be more or less useless. Almost half of the students (11/24) thought the visualizations helped them perceive interesting issues, such as time management (8/24). According to some students, this kind of visualization could be useful for the teachers $(6 / 24)$ for utilizing in development of instructional design.

"The statistics can offer useful information to the teachers for developing the course, and especially improve the schedules of the course." - Respondent 6

Each of the students were also offered a personalized interactive visualization (\#3), that was similar to the visualization in Fig. 4, but presented their own, individual activity and participation during the course using dimensions of time, unique viewers, views, and date. Only a quarter of the students $(26 \%)$ found this visualization to be useful, and over half of them $(56 \%)$ found the visualization to be useless. According to the latter students, the visualizations offered information about their own activity and participation that they already knew.

"The visualization did not tell me anything new that I did not know before." - Respondent 5

While some students (7) considered the visualization useful for monitoring their own activity, two of the students mentioned that the visualization was discouraging and upsetting.

"Analyzing own activity and performance is always useful. It is possible to see, is there something that need to improve or to make more effective." - Respondent 8

"It reminds you of low level of activity. It makes you feel laziness and inefficiency, even though you work hard all the time for doing home works. On the other hand, it 


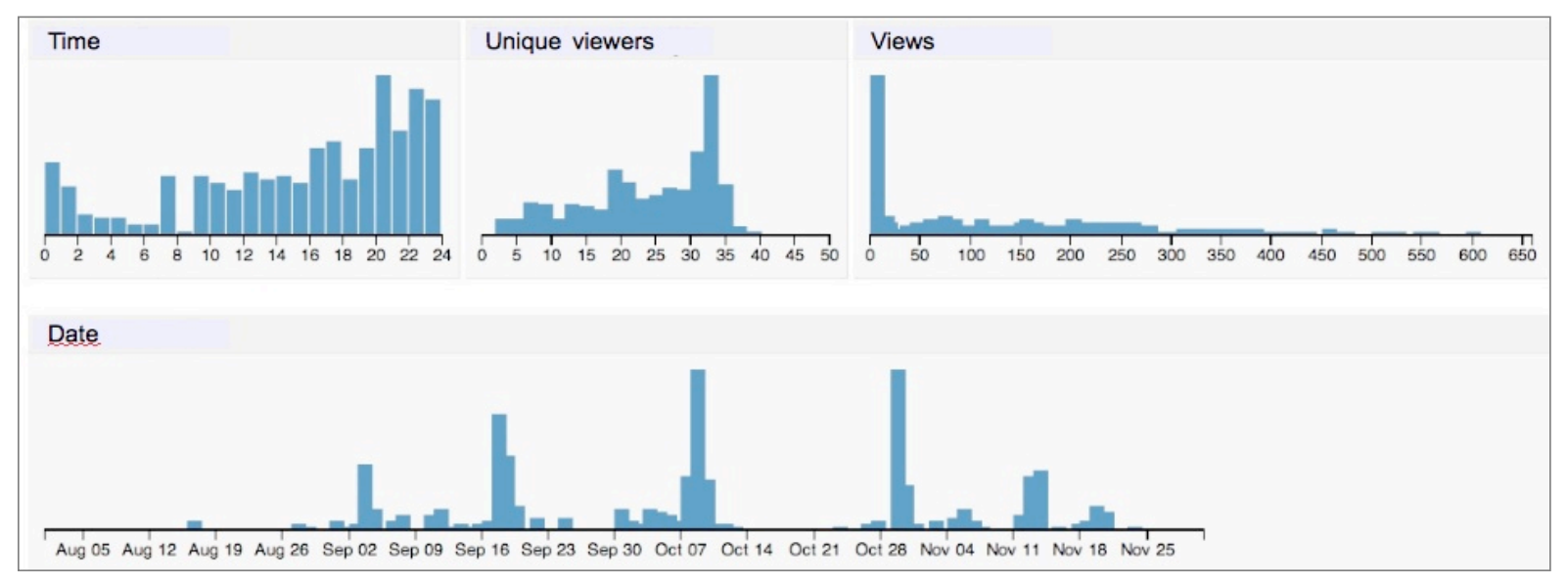

Figure 4. Activity of the students during the course according time, unique viewers, views, and date.

tells you that you could be more active in this course." Respondent 14

The students were also asked what kind of visualization would be useful for them. One quarter $(25 \%)$ thought the visualizations did not offer any value, while most of the students $(75 \%)$ considered the visualizations are useful in general. The students mentioned several issues worth visualizing, such as content of the learning material, keywords related to the messages, and how activity and participation are related to final scores.

\section{Online students' opinions on procrastination}

The phenomenon of procrastination was identified and verified by each of the visualizations presented. The students mentioned several reasons for procrastination, for example pressure, due to other courses and tasks; attitudes, such as laziness and inefficiency; external pressure as a motivating factor; and working habits (i.e. tendency to complete tasks on time, but submitted late after reading the answers of other students). When the students were asked to indicate what they considered to be the main reason for their procrastination, over half of the students $(14 / 24)$ mentioned pressure, due to other courses and tasks.

"According to my opinion, nowadays there are so many courses and weekly assignment in universities, that you have to submit something almost every day, which cause that submitting is delayed close to the deadline." Respondent 9

A third of the students mentioned that attitudes such as laziness and inefficiency associated with procrastination are natural for humans.

"It is natural for humans to postpone things as long as possible." - Respondent 13

Eight students out of the 24 mentioned that external pressure was the most motivating factor for completing the tasks, which caused the last-minute performance.

"It is easy to motivate yourself when you are forced [to do something]." - Respondent 22

Some of the students (4) mentioned working habits as a reason for procrastination.

"If you are uncertain about your answer, you can reflect your opinions towards answers written by other stu- dents and submit your own answer later on." - Respondent 5

According to the students' answers, procrastination can have a positive or negative impact on learning. Most of the students (21) thought procrastination had a negative impact on their learning, mainly due to lack of time. When the majority of the students submitted their answers just before the deadline, true conversation among them was impossible. The students also felt there was not enough time to develop a sufficient knowledge of the subject matter or to complete the assignments successfully. In addition, some of the students mentioned that procrastination decreased motivation and caused feelings of duress and stress.

"The students complete their assignments quickly and in hurry. There is almost no time to absorb [new information]." - Respondent 12

"Active conversation is possible only at the last moments." - Respondent 1

"[Procrastination] undermine learning. Stress level increase and subject matter is becoming unpleasant (you starting to wonder why do you have to do that)." - Respondent 24.

Three students mentioned that procrastination had a positive impact on their learning, by helping them schedule and divide the workload for the course. They also felt that external pressure motivated them to concentrate better on the subject matter.

"...The deadline culture do not have any negative impact on my learning. It only helps me to structure a schedule for my learning." - Respondent 3

\section{Usefulness of visualizations from the teacher's viewpoint}

According to the analysis of documents produced by design team the visualizations simplified the monitoring of the activities of individuals or groups, and helped to identify students' undesirable behavior, such as procrastination.

The time-driven animation presenting the development of the students' activity (\#1) demonstrates the phenomenon of procrastination very clearly (Figs. 1-3). Visualizing the evolution of the students' participations helped the teacher discover the students' burst-like behavior, and 
provide immediate guidance or improvement on schedules of the course.

The interactive visualization \#2 allowed the teacher to explore the students' activity and participation history by using live histograms. The histograms present the distribution of students' participation during the entire course. All peaks in the histogram are at the assessment due date, which indicates a high tendency of procrastination (Fig. 4). For the teacher this interactive histogram offered possibilities to monitor level of the students participation during the course, and filter information by clicking and dragging on the charts for identifying students who were more passive (or active) than others during certain period of time.

\section{DISCUSSION}

The IISLab at the TUT organized a teaching experiment in autumn 2012. In order to encourage students to work together, learn from each other, and develop and practice their interaction, collaboration, and networking skills, the TUT Circle social media service was used as a learning environment. In order to promote the students' participation and activate their thinking, the students were required to answer assignment questions by presenting their opinions, arguments, and comments on a course discussion forum. Active regular participation during a course is important for peer learning. If students are actively involved with the course content over a long period of time, they are more likely to develop a good understanding of the subject matter and be able to commit it to long-term memory. However, if they only deal with the matter right before a deadline, they will only use their working memory and lose the learned matter in the long run [3] [4] [18] [19].

During the teaching experiment in 2011, the main problems were the students' burst-like behavior, and the procrastination that made true conversation difficult and negatively influenced peer learning. The students reported that they did not have sufficient time to discuss and develop a deep understanding of the subject matter. Moreover, voluntary participation remained at a low level despite attempts to motivate the students to participate by offering extra points to do so [17] [20].

Based on the results from this teaching experiment, the instructional design of the course carried out in 2012 was greatly improved. Students were offered only six assignments, rather than nine, in order to give them more time to discuss theoretical issues. To promote active participation, the students were required to write two or three messages, instead of one message, to complete each task. The students were also motivated to avoid procrastination by offering the addition of extra points to their final scores if they wrote at least one message during the first three days after the assignment was opened [19].

In addition, the students were helped to monitor and evaluate their participation and activity levels during the course by offering them three different visualizations based on the information about the students actions in the learning environment, which were recorded in the log data of the TUT Circle. The first visualization (\#1) was a timedriven animation presenting the development of the students' activity, such as returning assignments as written messages during the course in the TUT Circle. The second (\#2) was an interactive visualization that presented the activity and participation of the student group during the course. The third (\#3) was a personalized interactive visualization that presented his/her own activity and participation.

According to the survey results, roughly half of the students thought that different peer-learning activities supported their learning, excluding sharing content, links, and other resources in the TUT Circle that $82 \%$ considered to support their learning. There were still some students (approximately $20 \%$ ) who found those activities not supporting their learning (See Table 1). In general, the students had a more positive experience in peer learning than the previous year's students [17] [20]. There could be several explanations for this. Firstly, the students participating in the 2012 course were different than students in the course of 2011. They could also be more motivated, or have more experience in learning interaction. Secondly, only the most motivated students provided their answers to the survey. Only 24 of the 33 students who participated in the course answered the survey, even though answering was part of their obligatory assignment. This suggests the most passive students did not answer the survey. Thirdly, the changes made in the instructional design of the course improved the quality of peer learning throughout.

During the course, only one in ten students seemed to avoid procrastination, while most of the students could not be motivated by the offer of additional points towards their final scores if they wrote at least one message during the first three days. According to the results, the main problems were procrastination and the students' burst-like participation that made true conversation difficult, resulting in a negative impact on learning. In all three visualizations offered to the students, procrastination, the tendency to postpone important tasks required to be completed by a specific deadline, was identified and verified. Students' burst-like behavior when they returned their assignments by writing all two or three messages required just before the deadline was observed during the entire course for all the assignments.

According to the survey results, the mains reasons for procrastination were: 1) pressure, due to other courses and tasks; 2) attitudes, such as laziness and inefficiency; 3) external pressure as a motivating factor; and 4) working habits (i.e. tendency to complete tasks on time, but submitted late after reading the answers of other students). The students were also asked about the impact of procrastination on their learning. Most of the students found that procrastination left them with no time for conversations, or for completing the assignments successfully. Some of the students found procrastination to decrease their motivation and cause feelings of duress and stress. The procrastinators seemed not to be a homogeneous group of students. Some of the students seemed to be active procrastinators making a conscious decision to procrastinate, whereas others, the passive procrastinators, seemed to have problems to complete their tasks on time [3]. The results from this survey were similar to those obtained in the teaching experiment of 2011 [17].

According to the survey results, roughly half of the students found that visualizations showing the students' participation and activity over time during the course useful. The visualizations helped to identify and verify the existence of procrastination, to see the activity in the course as a whole, and to narrow down the inspection period to get more detailed information, and perhaps increase the stu- 
dents' motivation to improve their learning performances. However, instead of motivating the students to participate more evenly, the visualizations also seemed to have a totally different impact on some students:

"I think that the visualizations were interesting, but they do not help me to study in different way. They mostly reinforce the bad habit to leave everything to the last minute like everybody else. It is more safe not to stand out in a crowd." - Respondent 22.

The visualization that represented information about the student's own activity and participation did not offer any new or interesting information to the students. Visualizations that help a student compare his/her own activity to other students' activity or visualizations presenting information on relationship between procrastination and academic performance would be more helpful and more motivating.

For the teacher, the visualizations helped monitor evolution of the students' activity and participation during the course, evaluate the impact of the designed assessment on the students' behavior, and identify undesirable behavior, such as procrastination. While time-driven animation presenting development of students' participation is fascinating and demonstrative, a traditional timeline could be more usable for visualizing activity over time in order to get insight into the evolution of participation [25]. Teachers could also benefit from interactive visualizations that help monitor and evaluate participation and activity of each individual students, for example, in order to identify students who might have problems with motivation or learning.

\section{CONCLUSION}

Half of the students found that different peer-learning activities supported their learning. However, it seems to be challenging to motivate students to avoid procrastination, and to work evenly throughout their course, which is important for peer learning. Offering students' possibilities to earn extra points to be added to their final scores proved largely ineffective. It is obvious that scheduling and assessment of assignment requires further improvement, for example, according to the suggestion made by one of the students:

"True conversation is decreasing, when all [the students] write [their answers] at same time. Could it be possible to think about so called dynamic deadlines? The students could have different deadlines depending on assignments. However, the same persons should not always have the first deadlines." - Respondent 5

Roughly half of the students found that visualizations showing the evolution and level of the students' participation and activity over time during the course were useful. The visualizations may have increased the students' motivation to participate more evenly and improve their learning performances. However, the visualizations seemed to have opposite impact on some students by reinforced the bad habit of procrastinating. If we wish to motivate students to be more active and more ongoing with their participation, information on the relationship between participation and academic performance should be presented to them. The visualizations helping a student compare his/her activity and participation to other students' activity could also be motivating. As a result, students may pro- cess their own objectives and perhaps change their behavior accordingly.

For the teacher, the visualizations provided valuable information to evaluate the students' study processes and identify undesirable behavior, such as procrastination, and evaluate the impact of the designed assessment. Further research is still required to investigate the phenomenon of procrastination from different viewpoints. Use of methods of learning analytics can provide interesting information to enhance teachers' understanding on how to support students to move from a deadline culture, towards ongoing active participation, how to encourage passive students to participate more actively, and the kinds of pedagogical interventions and instructional designs needed to promote peer learning. However, it is also important to realize that there are some crucial issues related to learning analytics, such as the privacy of data and results, including personal information and the protection of students' identities.

\section{ACKNOWLEDGMENT}

The design, technological development, and implementation of visualizations \#1-3 are courtesy of Juho Koro, at the Intelligent Information Systems Laboratory, Department of Mathematics, Tampere University of Technology, juho.koro@tut.fi.

\section{REFERENCES}

[1] J. Annala, M. Mäkinen, P. Svärd, K. Silius, and T. Miilumäki, "Online community environment promoting engagement in higher education," SLS J. - Stud. for the Learning Soc., vol. 2, pp. 75-86, 2012. http://dx.doi.org/10.2478/v10240-012-0007-0

[2] L.Y. Muilenburg and Z.L.Berge, "Student Barriers to Online Learning: A factor analytic study, "Distance Education, vol. 26, no. 1, May 2005, pp. 29-48, 2005.

[3] N. Michinov, S. Brunot, O. Le Bohec, J. Juhel, and M. Delaval, "Procrastination, participation, and performance in online learning environments," Computer \& Education, vol. 56, no. 1, pp. 243252, 2011. http://dx.doi.org/10.1016/j.compedu.2010.07.025

[4] A. Soller, "Supporting Social Interaction in an Intelligent Collaborative Learning System," Int. J. of Artificial Intelligence in Education, vol. 12, no. 1, pp. 40 - 62, 2001.

[5] P. Steel, "The nature of procrastination: a meta-analytic and theoretical review of quintessential self-regulatory failure," Psychological Bulletin, vol. 131, no. 1, pp. 65-94, 2007. http://dx.doi.org/10.1037/0033-2909.133.1.65

[6] S. Buckingham and R. Ferguson, "Social Learning Analytics," Educational Technology \& Society, vol. 15, no. 3, pp. 3-26, 2012.

[7] W. Greller, and H.Drachsler, "Translating Learning into Numbers: A Generic Framework for Learning Analytics," Educational Technology \& Society, vol. 15, no. 3, pp. 42-57, 2012.

[8] G. Siemens and D. Gasevic, "Guest Editorial - Learning and Knowledge Analytics," Educational Technology \& Society, vol. 15 , no. 3, pp. 1-2, 2012.

[9] C. Romero and S. Ventura, "Educational Data mining: A survey from 1995 to 2005," Expert Systems with Applications, vol. 33, Issue 1, July 2007, pp. 135-146, 2007.

[10] P. Drázdilová, G. Obadi, K. Slaninová, J. Martinovic, and V. Snásel, "Analysis and Visualization of Relations in eLearning," in Computational Social Network Analysis: Trends, Tools and Research Advances, A. Abraham, A-E. Hassanien and V. Snásel, Eds. London: Springer-Verlag London, 2010. doi: http://dx.doi.org/10.1007/978-1-84882-229-0_11,

[11] T. Elias, Learning Analytics: Definitions, Processes, and Potential, http://learninganalytics.net/LearningAnalyticsDefinitionsProc essesPotential.pdf

[12] M. Berg, Human abilities to perceive, understand, and manage multidimensional information with visualizations, Doctoral Dissertations 30/2012. Helsinki: Unigrafia Oy. 2012. http://lib.tkk.fi/ Diss/2012/isbn9789526045498/isbn9789526045498.pdf 


\section{SPECIAL FOCUS PAPER \\ STUDENTS' PARTICIPATION IN A SOCIAL MEDIA ENHANCED LEARNING ENVIRONMENT}

[13] J-D. Fekete, J.J. van Wijk, J.T. Stasko, and C. North, "The Value of Information Visualization," in Information Visualization - Human-Centered Issues and Perspectives, LNCS 4950, A. Kerren, J.T. Stasko, J.-D. Fekete, C. North, Eds. Springer, pp. 1-18, 2008.

[14] K. Silius, M. Kailanto, and A-M. Tervakari, "Evaluating the quality of social media in an educational context," Int. J. of Emerging Technologies in Learning, vol. 6, no. 3, pp. 21-27, 2011. http://dx.doi.org/10.3991/ijet.v6iS2.1655

[15] K. Silius et al., "Programming of hypermedia - course implementation in social media," in Proc. 2011 2nd Int. Congr. on Comput. Applicat. and Computational Sci. Advances in Intelligent and Soft Computing, vol. 144/2012, pp. 369-376, 2012. doi: http://dx.doi.org/10.1007/978-3-642-28314-7 50

[16] K. Silius et al., "Developing an online publication - collaborating among students in different disciplines," in Proc. 2011 2nd Int. Congr. on Comput. Applicat. and Computational Sci. Advances in Intelligent and Soft Computing, vol . 144/2012, pp. 361-367, 2012. doi: http://dx.doi.org/10.1007/978-3-642-28314-7 49.

[17] A-M. Tervakari, K. Silius, T. Tebest, J. Marttila, M. Kailanto, and J. Huhtamäki, "Peer learning in Social Media Enhanced Learning," Int. J. of Emerging Technologies in Learning, vol. 7, issue 3, 35-42, 2012. http://dx.doi.org/10.3991/ijet.v7i3.2173

[18] D. Boud, and A. Lee, "Peer learning as pedagogic discourse for research education," Studies in Higher Education, vol. 30, no. 5, pp. $501-516,2005$. http://dx.doi.org/10.1080/03075070500249 138

[19] D. Boud, R. Cohen, and J. Sampson, "Peer learning and assessment," Assessment and Evaluation in Higher Education, vol. 24, no. 4, pp. 413-426, 1999 http://dx.doi.org/10.1080/0260 293990240405

[20] A-M. Tervakari, J. Marttila, M. Kailanto, J. Huhtamäki, J. Koro, and K. Silius, "Developing Learning Analytics for TUT Circle," in Proc. of Open and Social Technologies for Networked Learning (OST'12), 30. July - 3.August 2012 in Tallinn, Estonia, 2012.

[21] K. Silius, and A-M. Tervakari, "An Evaluation of the Usefulness of Web based Learning Environments, The Evaluation Tool into the Portal of Finnish Virtual University," in Proc. of mENU 2003 - Int. Conf. on University Networks and E-learning 2003, 8-9 May 2003 in Valencia, Spain, V.Pearrocha et al. Eds., 2003.
[22] K. Silius, and A-M. Tervakari, "Variety of Quality Experiences on Web-Based Courses," in Proc. of the 7th IEEE Int. Conference on Advanced Learning Technologies ICALT 2007, July 18-20 2007 in Niigata, Japan, J. M. Spector et al. Eds., pp. 858-861, 2007. doi: http://dx.doi.org/10.1109/ICALT.2007.278

[23] J. Rogers, "New product Adaption and Diffusion," The J. of Consumer Research, 2(4), 290-301, 1976. http://dx.doi.org/10.1086/ $\underline{208642}$

[24] J. Preece, Y. Rogers, and H. Sharp, Interaction design: Beyond human-computer interaction. New York: John Wiley \& Sons, 2002.

[25] K. Still, J. Huhtamäki, M. Isomursu, J. Lahti, and K. KoskelaHuotari, "Analytics of the Impact of User Involvement in the Innovation Process and its Outcomes. Case study: Media-Enhanced Learning (MEL) service," in Proc. of the $4^{\text {th }}$ World Conference on Educational Sciences, 2 - 5 February 2012 in Barcelona, Spain, 2012.

\section{AUTHORS}

A.- M. Tervakari is with Intelligent Information Systems Laboratory, Department of Mathematics at Tampere University of Technology, Tampere, Finland (e-mail: anne.tervakari@tut.fi).

K. Silius is with Intelligent Information Systems Laboratory, Department of Mathematics at Tampere University of Technology, Tampere, Finland (e-mail: kirsi.silius@tut.fi).

M. Kailanto is with Intelligent Information Systems Laboratory, Department of Mathematics at Tampere University of Technology, Tampere, Finland (e-mail: meri.kailanto@tut.fi).

This work was supported in part by European Social Fund, North Ostrobothnia Centre for Economic Development, Transport and the Environment. It is an extended and modified version of a paper presented at the EDUCON2013 conference held at Technische Universität Berlin, Berlin, Germany from March 13-15, 2013. Submitted 06 May 2013. Published as re-submitted by the authors 25 July 2013. 